\title{
Ameliorative Effect of Allopurinol on Vascular Complications of Insulin Resistance
}

\author{
Hany M. El-Bassossy, ${ }^{1,2}$ Ahmed A. Elberry, ${ }^{3,4}$ Ahmad Azhar, ${ }^{5}$ \\ Salah A. Ghareib, ${ }^{1}$ and Abdulrahman M. Alahdal ${ }^{3}$ \\ ${ }^{1}$ Department of Pharmacology and Toxicology, Faculty of Pharmacy, King Abdulaziz University, Jeddah 21589, Saudi Arabia \\ ${ }^{2}$ Department of Pharmacology, Faculty of Pharmacy, Zagazig University, Zagazig 44519, Egypt \\ ${ }^{3}$ Department of Clinical Pharmacy, Faculty of Pharmacy, King Abdulaziz University, Jeddah 21589, Saudi Arabia \\ ${ }^{4}$ Department of Pharmacology, Faculty of Medicine, Beni Suef University, Beni Suef 62511, Egypt \\ ${ }^{5}$ Department of Pediatrics, Faculty of Medicine, King Abdulaziz University, Jeddah 21589, Saudi Arabia
}

Correspondence should be addressed to Ahmed A. Elberry; berry_ahmed@yahoo.com

Received 20 October 2014; Accepted 23 January 2015

Academic Editor: Raffaele Marfella

Copyright (c) 2015 Hany M. El-Bassossy et al. This is an open access article distributed under the Creative Commons Attribution License, which permits unrestricted use, distribution, and reproduction in any medium, provided the original work is properly cited.

\begin{abstract}
The aim of the current study was to evaluate the possible protective effect of allopurinol (Allo) on experimentally induced insulin resistance (IR) and vascular complications. Rats were divided into four groups: control, IR, allopurinol-treated IR (IR-Allo), and allopurinol-treated control (Allo). IR was induced by adding fructose and high fat, high salt diet for 12 weeks. The results showed that Allo has alleviated the increased level of TNF- $\alpha$ and the systolic, diastolic, mean, and notch pressure observed in IR with no change in pulse pressure. In addition, Allo decreased the heart rate in the treated group compared to IR rats. On the other hand, it has no effect on increased levels of insulin, glucose, fructosamine, or body weight gain compared to IR group, while it increased significantly the insulin level and body weight without hyperglycemia in the control group. Moreover, Allo treatment ameliorated increased level of 4HNE, Ang II, and Ang R1. In conclusion, the results of the current study show that Allo has a protective effect on vascular complications of IR which may be attributed to the effect of Allo on decreasing the TNF- $\alpha, 4 \mathrm{HNE}$, Ang II, and Ang R1 as well as increasing the level of insulin secretion.
\end{abstract}

\section{Introduction}

Insulin resistance (IR) is associated with obesity and characterized by its metabolic consequences, including hyperglycemia, dyslipidemia, and hypertension [1]. These metabolic consequences are known collectively as "metabolic syndrome" (MetS) and are potent risk factors for adverse clinical outcomes [2]. IR has been found to be associated, directly and indirectly, with cardiovascular complications, including atherosclerosis that may lead to myocardial infarction and stroke [3].

Moreover, obesity is associated with increased production of proinflammatory adipokines, including monocyte chemoattractant protein-1, interleukin-6 (IL-6), and tumor necrosis factor- $\alpha$ (TNF- $\alpha$ ). They contribute to chronic, low-grade inflammation and play a pivotal role in the development of insulin resistance $[4,5]$.

Fructose intake has been directly linked to hyperuricemia [6], which may result in obesity and MetS [7, 8]. The mechanism by which uric acid (UA) induces the development of MetS may be due to UA inhibition of nitric oxide synthase and induction of endothelial dysfunction $[9,10]$. Recent evidence supports the concept that hyperuricemia itself can be a significant and independent cardiovascular risk factor [11]. Lowering UA in fructose-induced MetS has been found to be associated with lowering BP, improving insulin sensitivity, and reducing hypertriglyceridemia, through improving endothelial and adipocyte dysfunction [12]. Therefore, the aim of the current study was to evaluate the effect of allopurinol, as a xanthine oxidase enzyme inhibitor reducing 
the level of UA, on insulin resistance induced experimentally in rats and its possible protective effect on the cardiovascular complications.

\section{Materials and Methods}

2.1. Drugs and Chemicals. The following drugs and chemicals were used: allopurinol and urethane (Sigma-Aldrich, St. Louis, MO, USA). Allopurinol and urethane were dissolved in distilled water.

2.2. Animals. Male Wistar rats weighing 120-140 g (King Fahd Center for Medical Research, King Abdulaziz University, Saudi Arabia) were housed in clear polypropylene cages (four rats per cage) and kept on equal durations of the darklight cycle, under constant environmental conditions. Rats received normal rodent pellet diet and water ad libitum. Experimental protocol was approved by the Research Ethics Committee of the Faculty of Medicine, King Abdulaziz University.

2.3. Study Protocol. Rats were randomly divided into four experimental groups (eight animals each) as follows: control, insulin resistant (IR), allopurinol-treated insulin resistance (IR-Allo), and allopurinol-treated control (Allo). IR was induced by adding fructose $(10 \%)$ to everyday drinking water and feeding rats on high fat, high salt diet (16\% crude protein, $28.2 \%$ crude fat, $2.8 \%$ crude fiber, $4.8 \%$ Ash, and $3.4 \%$ salt) for 12 weeks, while control animals receive tap water and standard diet (20\% crude protein, $4 \%$ crude fat, $3.5 \%$ crude fiber, $6 \%$ Ash, and $0.5 \%$ salt $)$. Allopurinol $\left(20 \mathrm{mg} \cdot \mathrm{kg}^{-1} \cdot \mathrm{day}^{-1}\right)$ was daily administered by dissolving in drinking water (90$110 \mathrm{mg} / \mathrm{L}$ ) depending upon water consumption [13]. Drinking water was measured every week and allopurinol concentration in drinking water was readjusted.

At the end of the study, animals were fasted 8 hours. The blood glucose level was determined. Then the rats were anesthetized by intraperitoneal injection of urethane $\left(1.5 \mathrm{~g} \cdot \mathrm{kg}^{-1}\right)$ and the invasive BP was recorded. Finally, venous blood was withdrawn and allowed to coagulate for $30 \mathrm{~min}$ at $4^{\circ} \mathrm{C}$ and then was centrifuged $\left(3000 \times \mathrm{g}, 4^{\circ} \mathrm{C}, 20 \mathrm{~min}\right)$ to separate serum. Serum was divided into aliquots and stored at $-20^{\circ} \mathrm{C}$ till being analyzed for insulin, TNF- $\alpha$, adiponectin, and lipid profile.

2.4. Serum Analysis. Glucose was determined in tail blood by a glucose meter (Bionime $\mathrm{GmBH}$ ) using noble metal electrode strips. Serum insulin level as well as fructosamine was measured by enzyme-linked immunosorbent assay (ELISA, Millipore, Billerica, MA, USA) that uses a plate coated with monoclonal anti-rat insulin antibodies.

The homeostasis model assessment of insulin resistance (HOMA-IR) (IR index) was calculated using the serum nonfasting glucose and insulin levels according to the equation of Matthews et al. [14]: HOMA-IR = glucose concentration $(\mathrm{mmol} / \mathrm{L}) \times$ insulin $(\mu \mathrm{U} / \mathrm{L}) / 22.5$.

Serum levels of UA, triglycerides (TG), total cholesterol (TC), and high density lipoprotein cholesterol (HDL-C) were determined using the ELITech assay kit (ELITech, Laindon, Essex, France). The low density lipoprotein cholesterol (LDLcholesterol) was computed using the Friedewald [15] equation: total cholesterol - (HDL-C + 1/5TG).

\subsection{Blood Pressure (BP) and Heart Rate (HR) Measurement.} Invasive $\mathrm{BP}$ was continuously recorded for 10 minutes by microtip catheter (Millar, Bella Vista, Australia) inserted in the thoracic aorta through the right carotid artery. The microtip catheter was connected to Power Lab Data Interface Module connected to a PC running LabChart professional software (v7.3, ADI Instruments, Bella Vista, Australia) containing BP module. The BP module detects and calculates different BP parameters like systolic BP, diastolic BP, mean BP, notch pressure, heart rate, cycle duration, ejection duration, and diastolic duration.

2.6. Measurement of TNF- $\alpha$ and Adiponectin. Serum TNF$\alpha$ and adiponectin levels were determined by ELISA using Quantikine kit (R\&D systems, Minneapolis, MN, USA) using rat TNF- $\alpha$ or rat adiponectin and antibodies raised against the rat TNF- $\alpha$ or rat adiponectin, respectively.

2.7. Immunofluorescent Studies. Immunofluorescence staining of 4-hydroxy-2-nonenal (4-HNE), Ang II, Ang R1, and collagen protein expression in rat paraffin embedded aortic sections $(5 \mu \mathrm{m})$ was carried out according to the method used in our previous works [16-18]. Fixed aortic tissue section slides were deparaffinized in xylene and rehydrated in ethanol and distilled water. Then, perforation is carried out by incubation with methanol at $-20^{\circ} \mathrm{C}$ for $30 \mathrm{~min}$ followed by washing with distilled water. Epitopes were retrieved (antigen retrieval) in citrate buffer for $30 \mathrm{~min}$ at $95^{\circ} \mathrm{C}$ followed by washing with PBS. Slides were then immediately transferred into a humidity chamber. Nonspecific binding sites were blocked (PBS containing 5\% NGS, 1\% BSA, and 0.1\% Triton) at room temperature for $1 \mathrm{~h}$. After the blocking, sections were washed $(3 \times 5 \mathrm{~min})$ with $\mathrm{PBS}$. Aortic sections were then incubated with the intended primary antibody diluted in blocking buffer at $4^{\circ} \mathrm{C}$ overnight. The sections were then washed $(3 \times 5 \mathrm{~min})$ with PBS followed by incubation with a fluorescent conjugated secondary antibody (dilution $1: 200$ in blocking buffer) for $1 \mathrm{~h}$ in dark. Then sections were washed $(3 \times 5 \mathrm{~min})$ with $\mathrm{PBS}$ and slides were dried and mounted with Prolong lasting mounting media. The slides were stored in dark overnight before examination with Zeiss LSM 780 confocal microscope (Carl Zeiss, Gottingen, Germany) at excitations (488 and $561 \mathrm{~nm}$ ) and filters (497542 and 596-655 $\mathrm{nm}$ ). Images were acquired with identical acquisition parameters, with minimum excitation and gain. Quantitative comparisons of images fluorescence were made with ImageJ software (National Institute of Health, Bethesda, MD, USA). For printing purposes, the level of the confocal images was equally adjusted after the fluorescence quantifications were carried out on unmanipulated images. Sections treated with the secondary antibody alone did not show specific staining while incubating the primary antibody with the blocking peptide significantly reduced the signal. 
TABLE 1: The effect of allopurinol (Allo) treatment on insulin resistance (IR) induced body weight changes and blood biochemical markers including uric acid, fructosamine, fasting blood glucose, and insulin compared to control group.

\begin{tabular}{|c|c|c|c|c|c|}
\hline & $\begin{array}{l}\text { Body weight gain } \\
\% \text { from baseline }\end{array}$ & Uric acid (pg/mL) & Fructosamine $(\mu \mathrm{mol} / \mathrm{L})$ & $\begin{array}{l}\text { Fasting blood glucose } \\
(\mathrm{mg} / \mathrm{dL})\end{array}$ & Insulin $(\mathrm{ng} / \mathrm{mL})$ \\
\hline Control group & $39.81 \pm 4.913$ & $0.95 \pm 0.15$ & $46.63 \pm 3.75$ & $73.29 \pm 2.86$ & $0.782 \pm 0.13$ \\
\hline IR group & $157.5 \pm 29.35^{* * *}$ & $1.18 \pm 0.08$ & $71.47 \pm 6.05^{* *}$ & $118.30 \pm 9.70^{* * *}$ & $3.149 \pm 0.31^{* *}$ \\
\hline IR-Allo Group & $115.5 \pm 16.60^{* *}$ & $0.55 \pm 0.10^{\# \#}$ & $61.33 \pm 1.92^{* *}$ & $112.20 \pm 0.86^{* * *}$ & $3.322 \pm 0.49^{* *}$ \\
\hline Allo group & $143.6 \pm 8.392^{* *}$ & $0.97 \pm 0.03$ & $52.00 \pm 3.29$ & $85.00 \pm 8.77$ & $2.822 \pm 0.32^{* *}$ \\
\hline
\end{tabular}

Values are expressed as the mean \pm SEM; $N=6-8$ animals.

${ }^{*} P<0.05,{ }^{* *} P<0.01$, and ${ }^{* * *} P<0.001$, compared with the corresponding control group values; ${ }^{\#} P<0.05$ and ${ }^{\# \#} P<0.01$ compared with the corresponding IR group values, by One-Way ANOVA and Newman-Keuls post hoc test.

TABLE 2: The effect of allopurinol (Allo) treatment on insulin resistance (IR) lipoprotein profile including total cholesterol (TC), low density lipoprotein (LDL), triglycerides (TG), and high density lipoprotein (HDL-C) compared to control group.

\begin{tabular}{lcccc}
\hline & TG $(\mathrm{mg} / \mathrm{dL})$ & TC $(\mathrm{mg} / \mathrm{dL})$ & LDLC $(\mathrm{mg} / \mathrm{dL})$ & HDL $(\mathrm{mg} / \mathrm{dL})$ \\
\hline Control group & $45.85 \pm 2.55$ & $50.15 \pm 2.42$ & $29.08 \pm 6.41$ & $13.75 \pm 2.85$ \\
IR group & $55.17 \pm 6.89$ & $48.50 \pm 4.29$ & $16.94 \pm 4.01$ & $21.19 \pm 2.58$ \\
IR-Allo group & $45.36 \pm 3.23$ & $53.72 \pm 4.56$ & $23.04 \pm 3.67$ & $21.07 \pm 2.50$ \\
Allo group & $47.04 \pm 2.94$ & $51.49 \pm 2.13$ & $23.10 \pm 2.10$ & $18.99 \pm 1.27$ \\
\hline
\end{tabular}

Values are expressed as the mean \pm SEM; $N=6-8$ animals, without any significant differences by One-Way ANOVA and Newman-Keuls post hoc test.

The used primary antibodies were rabbit polyclonal anti-Ang II (1:2000, Phoenix Pharmaceuticals Inc., Burlingame, CA, USA), mouse monoclonal anti-angiotensin II type 1 receptor (1:133, Abcam, Cambridge, MA, USA), mouse monoclonal anti-collagen type I ( $1: 1000$, Abcam), and rabbit polyclonal anti-4HNE (1:250, Millipore, Billerica, MA, USA). The used secondary antibodies were Alexa Fluor $\left(\lambda_{\text {ex }}=488\right)$ conjugated goat anti-mouse and Alexa Fluor $\left(\lambda_{\mathrm{ex}}=594\right)$ conjugated goat anti-rabbit $(1: 200$, Life Technologies, Grand Island, NY, USA).

2.8. Statistical Analysis. Values are expressed as mean \pm SEM. Statistical analysis was performed by analysis of variance (ANOVA) followed by Newman-Keuls' post hoc test using a computer based fitness program (Prism 5, GraphPad, CA, USA).

\section{Results}

3.1. Effect of Allopurinol on Body Weight Gain. Body weight gain of the IR group was significantly increased $(P<0.001)$ compared to control group. This increase was ameliorated in IR-Allo group but still significantly higher than the control group $(P<0.01)$. Body weight gain was also higher in Allo group $(P<0.01)$ (Table 1$)$.

3.2. Effect of Allopurinol on Biochemical Blood Markers and IR Index. Regarding UA it was increased in IR group, but this increase was nonsignificant. Treatment with Allo has decreased the level of UA significantly $(P<0.01)$ in IR-Allo group, while there was no effect in Allo group. Fructosamine, fasting blood glucose, and insulin were significantly increased in IR group $(P<0.01, P<0.001$, and $P<0.01$, resp.). These failed to be ameliorated by Allo in IR-Allo group. Allo

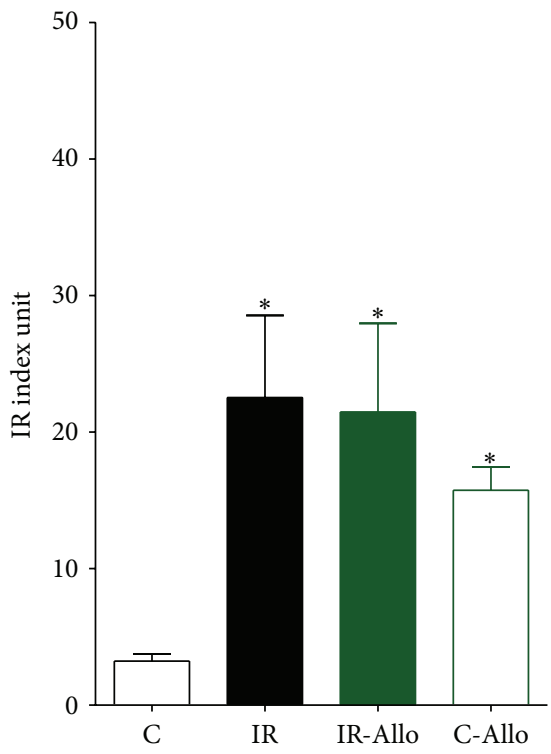

FIGURE 1: The effect of allopurinol (Allo) treatment on insulin resistance (IR) index.

showed no effect on fructosamine or fasting blood glucose in Allo group but showed significant increase $(P<0.01)$ in insulin level compared to control group (Table 1). IR index was increased in all treated groups compared to the control untreated group. This increase was significant in IR and IRAllo groups $(P<0.05)$ (Figure 1$)$.

3.3. Effect of Allopurinol on Lipid Profile. Table 2 revealed that IR model in the current study failed to show any significant changes regarding the fasting lipoprotein profile. However, there was tendency to increase both TG and HDL-C, but this 
TABLE 3: The effect of allopurinol (Allo) treatment on insulin resistance (IR) induced BP cycle duration changes measured in seconds compared to control group.

\begin{tabular}{lcccc}
\hline & Total cycle duration & Ejection duration & Diastolic duration & Time to peak \\
\hline Control group & $0.196 \pm 0.007$ & $0.069 \pm 0.002$ & $0.127 \pm 0.007$ & $0.040 \pm 0.003$ \\
IR group & $0.190 \pm 0.011$ & $0.062 \pm 0.004$ & $0.123 \pm 0.01$ & $0.028 \pm 0.002$ \\
IR-Allo group & $0.220 \pm 0.012$ & $0.104 \pm 0.013^{\#}$ & $0.118 \pm 0.010$ & $0.038 \pm 0.002$ \\
Allo group & $0.194 \pm 0.009$ & $0.066 \pm 0.005$ & $0.129 \pm 0.007$ & $0.036 \pm 0.004$ \\
\hline
\end{tabular}

Values are expressed as the mean \pm SEM; $N=6-8$ animals.

${ }^{*} P<0.05,{ }^{* *} P<0.01$, and ${ }^{* * *} P<0.001$, compared with the corresponding control (C) group values; ${ }^{\#} P<0.05,{ }^{\# \#} P<0.01$, and ${ }^{\# \# \#} P<0.001$ compared with the corresponding IR group values, by One-Way ANOVA and Newman-Keuls post hoc test.

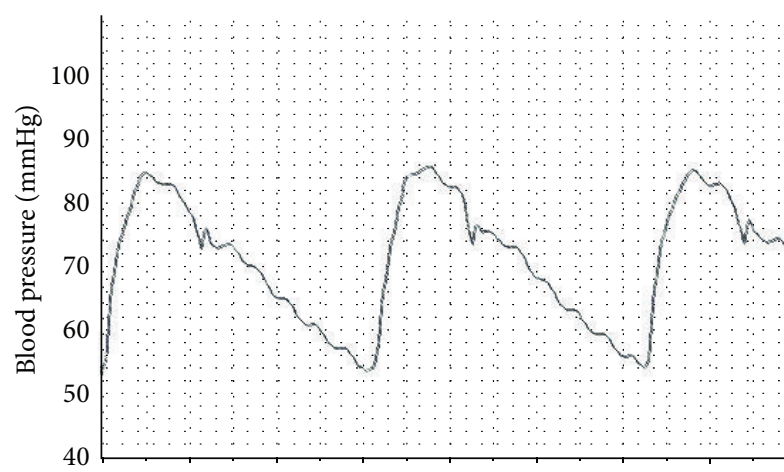

(a)

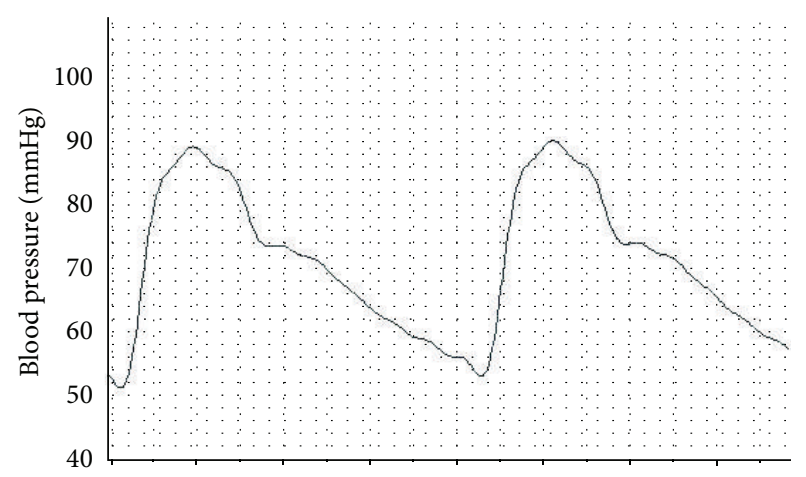

(c)

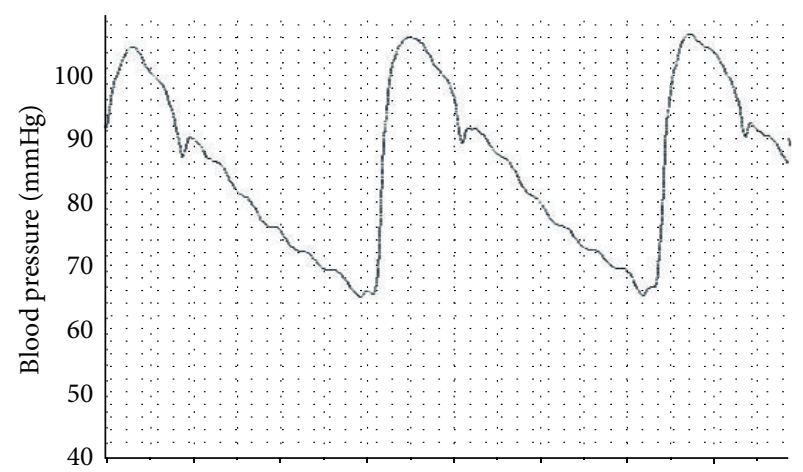

(b)

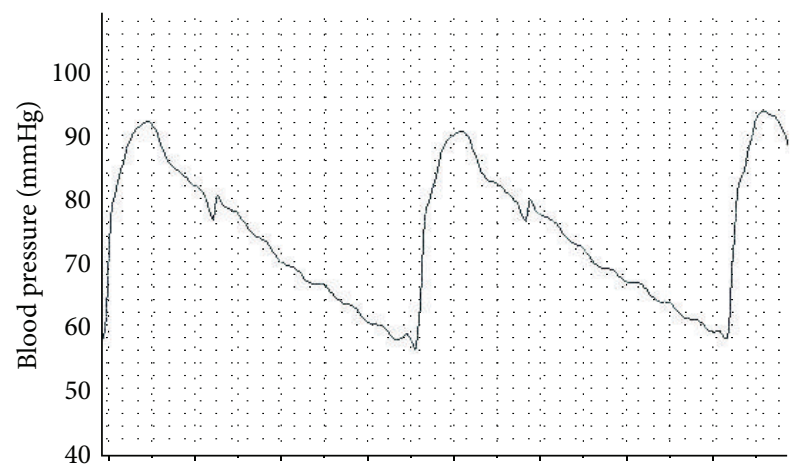

(d)

FIGURE 2: The effect of allopurinol on insulin resistance induced blood pressure changes in BP tracing. Normal control BP (a) shows control systolic and diastolic pressure. IR BP tracing (b) shows increase of both systolic and diastolic BP. IR + allopurinol (c) shows nearly normalized diastolic BP with significant decrease of the elevated systolic BP and increase in the diastolic time. Control + allopurinol (d) shows nearly normal systolic and diastolic BP with minimal increased diastolic time.

increase was nonsignificant. Allo treatment has decreased nonsignificantly the TG level and increased nonsignificantly the LDL-C level with no effect on TC or HDL-C in either IRAllo group or Allo group.

3.4. Effect of Allopurinol on BP Changes. BP tracing showed normal BP values including systolic pressure, diastolic pressure, mean arterial pressure, and dicrotic notch pressure as well as normal heart rate in both control group and Allo group (Figures 2 and 3). Moreover, cycle duration in all rats in both control and Allo groups was found to be normal (Table 3). IR has significantly increased systolic $(P<0.01)$, diastolic $(P<0.01)$, mean $(P<0.01)$, pulse $(P<0.01)$, and dicrotic notch $(P<0.01)$ pressures. It also increased the heart rate, but this increase was nonsignificant. Treatment of IR with Allo has significantly decreased the elevated systolic $(P<0.05)$, diastolic $(P<0.05)$, mean $(P<0.05)$, and dicrotic notch $(P<0.05)$ pressures with no effect on pulse pressure. Moreover, Allo has decreased the heart rate compared to control and IR groups (Figures 2 and 3 ).

Regarding the cycle duration IR has no significant changes, including total cycle duration, ejection duration, diastolic duration, and time to peak. In addition, Allo has no effect in all cycle durations except for the ejection duration where it has significantly $(P<0.05)$ increased compared to the control group. 


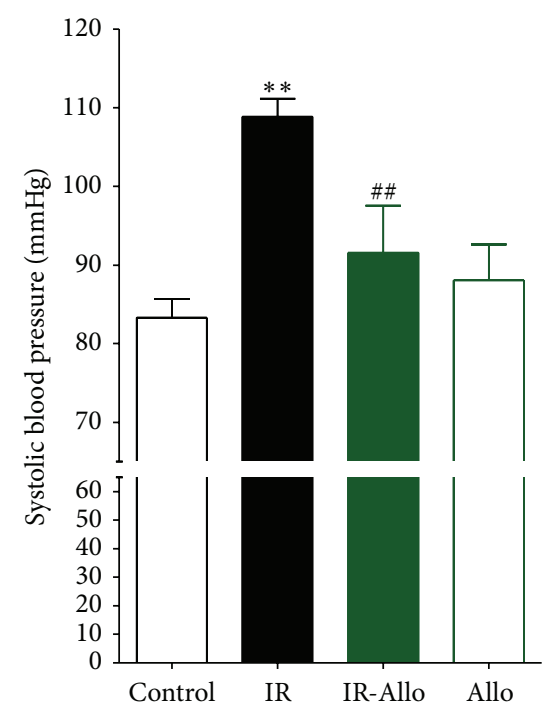

(a)

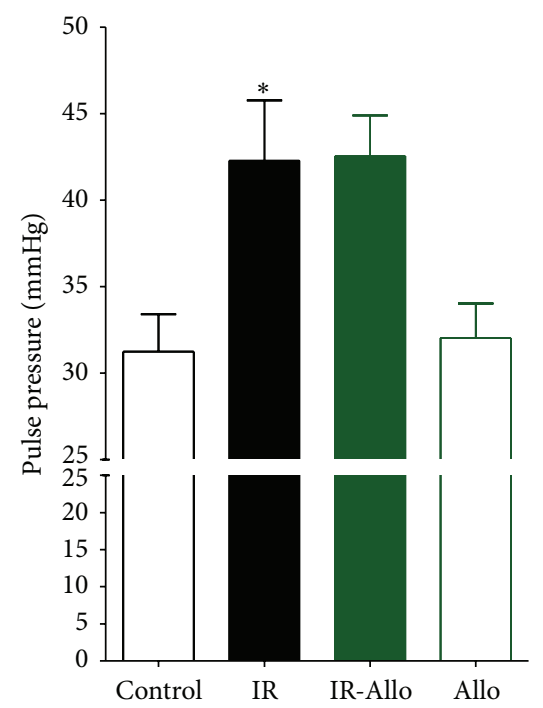

(d)

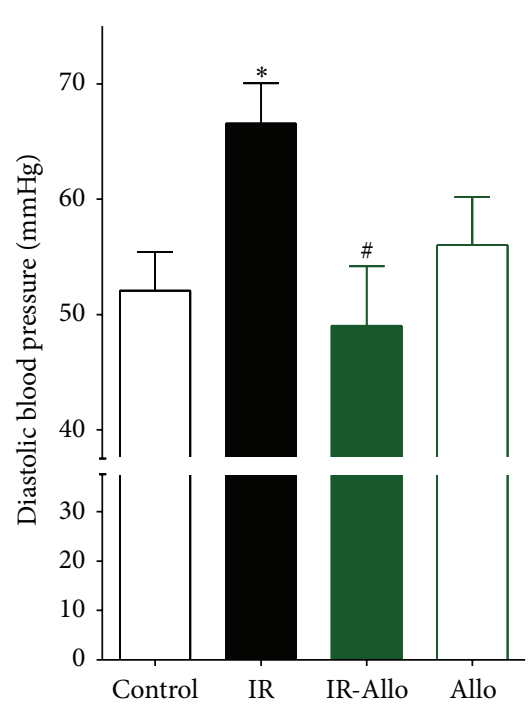

(b)

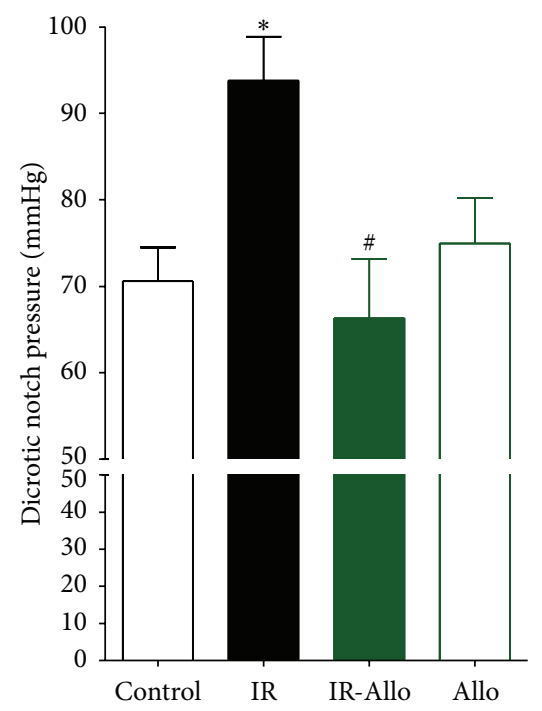

(e)

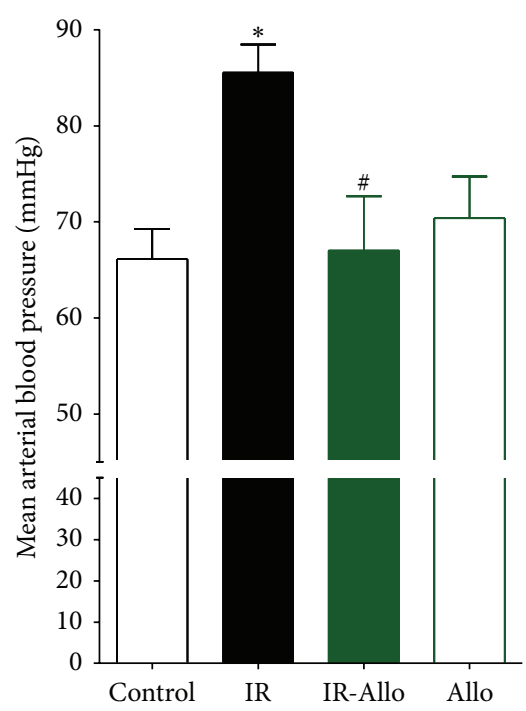

(c)

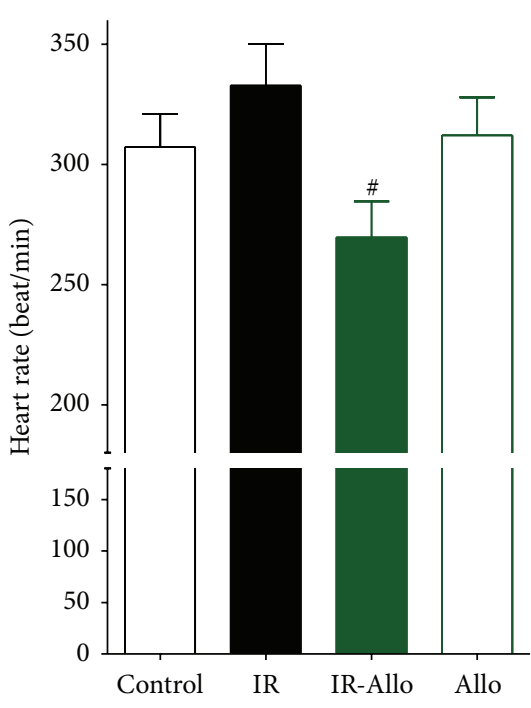

(f)

FIGURE 3: The effect of allopurinol (Allo) treatment on insulin resistance (IR) induced BP changes measured in mmHg and heart rate measured as beats/minute compared to control group (C). (a) Systolic BP, (b) diastolic BP, (c) mean arterial BP, (d) pulse pressure, (e) dicrotic notch pressure, and (f) heart rate. Values are expressed as the mean \pm SEM; $N=6-8$ animals; ${ }^{*} P<0.05$ and ${ }^{* *} P<0.01$ compared with the corresponding control (C) group values; ${ }^{\#} P<0.05$ and ${ }^{\# \#} P<0.01$ compared with the corresponding IR group values, by One-Way ANOVA and Newman-Keuls post hoc test.

3.5. Effect of Allopurinol on TNF- $\alpha$ and Adiponectin. TNF$\alpha$ was significantly increased in IR group $(P<0.001)$. Allo treatment was significantly $(P<0.01)$ able to decrease this increased level to the nearly normal control value, while Allo treatment has no effect on Allo group (Figure 4(a)). Regarding adiponectin, IR showed no effect on its level and the treatment with Allo has no effect also in IR-Allo group. Moreover, Allo treatment in Allo group revealed no effect on the level of adiponectin (Figure 4(b)).

3.6. Immunofluorescent Results. IR group showed significant increase in $4 \mathrm{HNE}(P<0.05)$ compared to control group. Allo treatment significantly $(P<0.01)$ ameliorated this increased level to the normal control values (Figure 5). On the other hand, IR caused no significant changes in Ang II or Ang R1 but Allo treatment caused significant decrease $(P<0.05)$ of both even when compared with normal control values (Figures 6 and 7). Regarding the aortic collagen, no significant changes were observed between all groups (Figure 8).

\section{Discussion}

In the present study, rats fed on fructose and high fat and high salt diet revealed IR evidenced by an increase in both insulin 


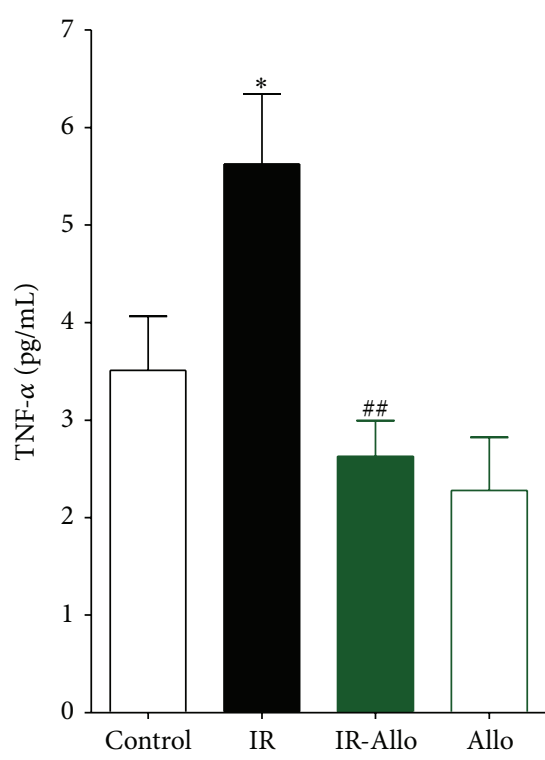

(a)

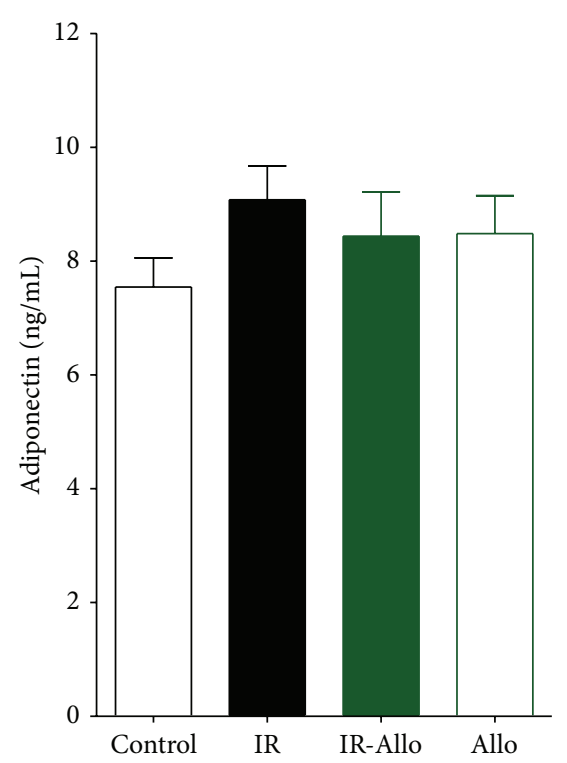

(b)

FIGURE 4: The effect of allopurinol (Allo) treatment on insulin resistance (IR) induced TNF- $\alpha$ (a) and adiponectin (b), where they are measured in $\mathrm{pg} / \mathrm{mL}$. Values are expressed as the mean \pm SEM; $N=6-8$ animals; ${ }^{*} P<0.05,{ }^{* *} P<0.01$, and ${ }^{* * *} P<0.001$, compared with the corresponding control group values; ${ }^{\#} P<0.05$ and ${ }^{\# \#} P<0.01$ compared with the corresponding IR group values, by One-Way ANOVA and Newman-Keuls post hoc test.

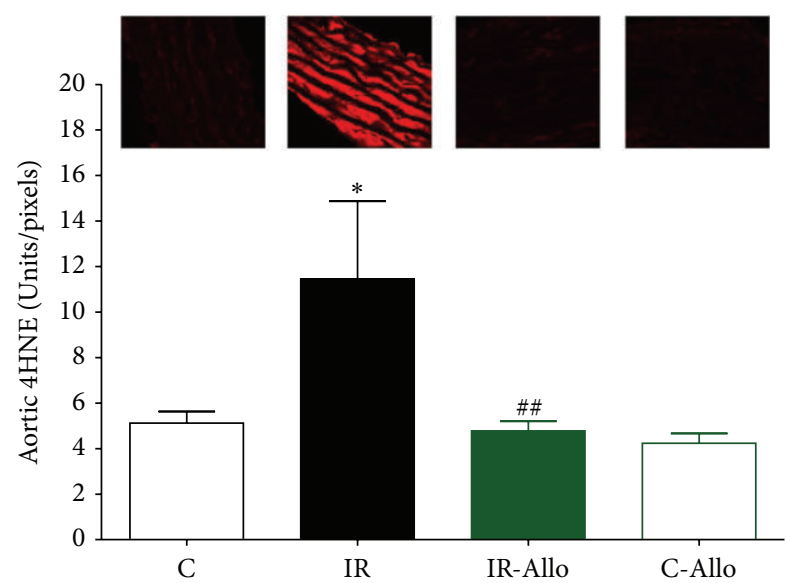

FIgURE 5: The effect of allopurinol (Allo) treatment on insulin resistance (IR) induced $4 \mathrm{HNE}$ changes, measured in Units/pixels. Values are expressed as the mean \pm SEM; $N=6-8$ animals; ${ }^{*} P<$ 0.05 , compared with the corresponding control group values; ${ }^{\# \#} P<$ 0.01 compared with the corresponding IR group values, by One-Way ANOVA and Newman-Keuls post hoc test.

and glucose levels. IR is an important predisposing factor for several clinical disorders, including type 2 diabetes, obesity, dyslipidemia, and hypertension [19]. Although dyslipidemia was not observed in the current study, obesity, increased levels of both glucose and insulin, and hypertension were clearly evident. Moreover, fructosamine, which is an indicator of the average blood glucose concentration over a short-medium period, has increased significantly in the IR model. The prevalence of hyperinsulinemia and IR rise with increasing

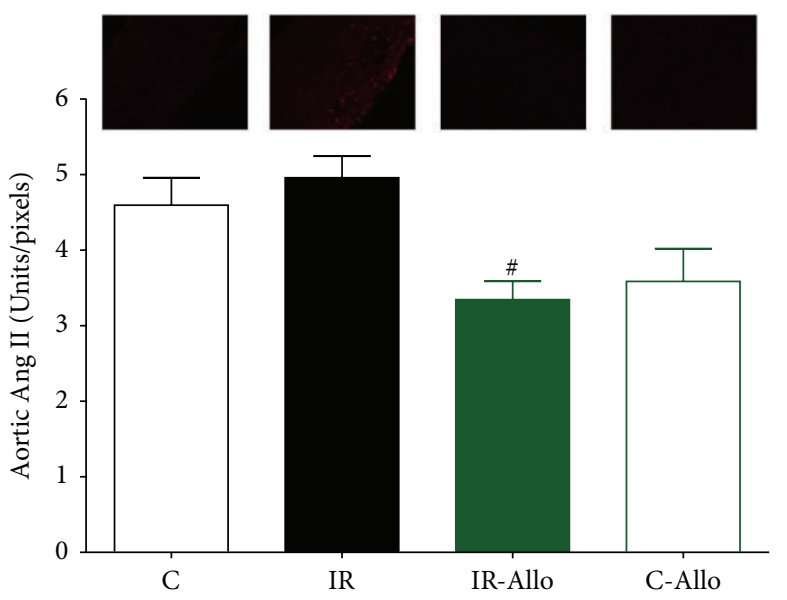

Figure 6: The effect of allopurinol (Allo) treatment on insulin resistance (IR) induced Ang II changes, measured in Units/pixels. Values are expressed as the mean \pm SEM; $N=6-8$ animals; ${ }^{*} P<$ 0.05 , compared with the corresponding control group values; ${ }^{\#} P<$ 0.05 compared with the corresponding IR group values, by One-Way ANOVA and Newman-Keuls post hoc test.

body mass index and obesity [20], but whether insulin causes these phenomena or is a compensatory response has remained unsettled for decades. The current study showed that Allo has increased the level of insulin without effect on glucose level and associated with increased body weight in control groups. This increase in the body weight may be explained by the allopurinol-induced secretion of insulin observed in the current study with subsequent increase in 


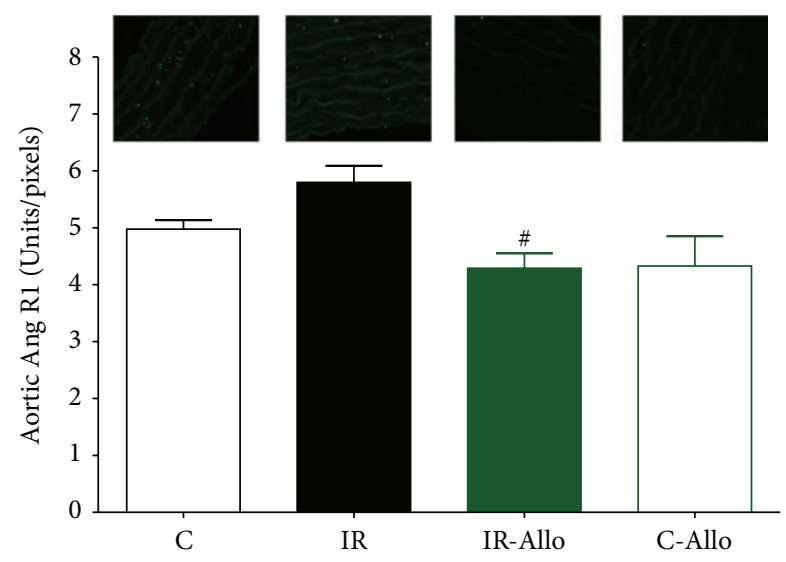

FIgURE 7: The effect of allopurinol (Allo) treatment on insulin resistance (IR) induced Ang R1 changes, measured in Units/pixels. Values are expressed as the mean \pm SEM; $N=6-8$ animals; ${ }^{\#} P<$ 0.05 compared with the corresponding IR group values, by One-Way ANOVA and Newman-Keuls post hoc test.

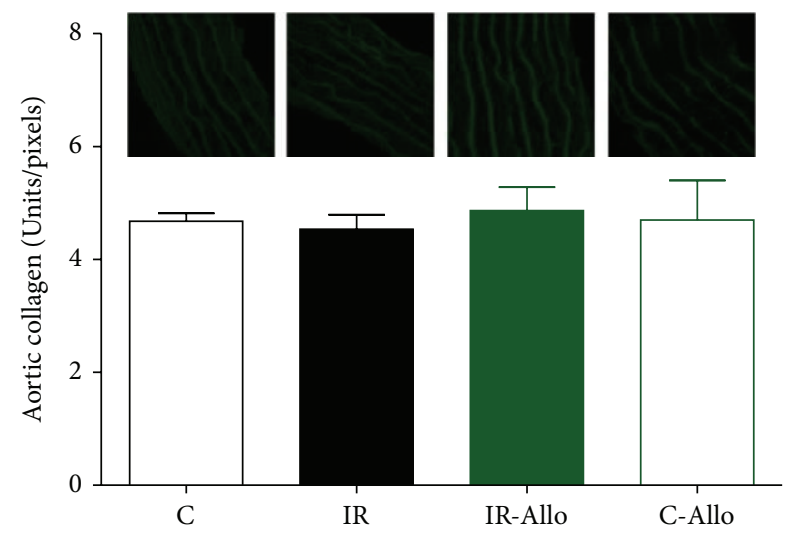

Figure 8: The effect of allopurinol (Allo) treatment on insulin resistance (IR) induced collagen changes, measured in Units/pixels. Values are expressed as the mean \pm SEM; $N=6-8$ animals, with no significant changes by One-Way ANOVA and Newman-Keuls post hoc test.

the glucose uptake in muscles and adipose tissue leading to weight gain with no effect on insulin resistance as the level of glucose was comparable to the normal control group. This finding may need more subsequent studies for accurate and further explanations. Regarding dyslipidemia, a possible explanation for insignificant change in the lipid profile is that fructose-induced hyperuricemia is maximal in the first few hours following ingestion of fructose [21] and is also dose-dependent [22]. Moreover, the small sample size used in the present study may be another explanation for this insignificant change in the lipid profile.

Clinical and experimental studies have assessed the relationship between hyperuricemia and hypertension and found that hyperuricemia might play a double role as a risk factor for hypertension and as a pathological condition enhanced by hypertension itself [11]. Moreover, many studies revealed that IR is a risk factor for cardiovascular disease [3,23]. Despite the fact that it was nonsignificant, the results of the present study demonstrated that IR caused an increase of the UA level with significant vascular complications including the systolic, diastolic, mean, pulse, and dicrotic notch pressure with no effect on the cycle durations or heart rate. Previous studies found that XO activity is increased by various cytokines, including TNF- $\alpha[24,25]$, which is significantly increased in the current study. Moreover, $\mathrm{XO}$ was found to be significantly elevated in a variety of vascular diseases including limb ischemia [26], coronary artery disease [27], and heart failure [28]. Circulating XO binds to glycosaminoglycans on the surface of endothelial cells where it is involved in the pathogenesis of endothelial injury $[29,30]$. In addition, our previous study demonstrated that TNF- $\alpha$ has an important role in IR and vascular impairment [31]. In contrast, the nonsignificant elevation of UA in the current study may be attributed to the fact that the present model is not the ideal model representing the hyperuricemia using $2 \%$ oxanic acid [9]. This may pay attention to the possibility that the effect of Allo is not dependant on decreasing the UA level, but due to effect on other byproducts of purine metabolism by $\mathrm{XO}$ as superoxide.

Moreover, hyperglycemia and hyperinsulinemia in IR may reduce arterial wall compliance by promoting plaque growth, vascular smooth muscle cell proliferation, and nonenzymatic glycosylation of vessel wall proteins [32, 33]. It was reported that the vascular endothelium expresses membrane insulin receptors and is a target for the biologic effects of insulin, which stimulate production of nitric oxide (NO) leading to vasodilatation [34]. This effect is blunted in cases of IR. Moreover, hyperglycemia itself increases the release of the vasoconstricting peptide endothelin-1 from cultured endothelial cells, offsetting the vasodilating actions of NO [35].

The results of the current study showed that Allo has alleviated the vascular complications of IR including systolic, diastolic, mean, and dicrotic notch pressures compared to the untreated IR group. The elevations in diastolic and notch BP are largely attributed to the increased peripheral arterial resistance [36], whereas pulse pressure reflects stiffening of large arteries [37]. Pulse pressure was not significantly changed in IR as a result of significant increase in both systolic and diastolic BP in IR group. The present study may provide an explanation for these palliative effects which may be related to the effect of Allo on increasing insulin secretion observed in the Allo control group which in turn have a vasodilator effect on blood vessels [34]. Moreover, previous studies found that Allo improves endothelial dysfunction and prevents the development of arteriosclerosis [38]. Moreover, inhibition of XO by Allo was found to improve endotheliumdependent dilation and reduced superoxide production in isolated coronary arterioles following ischemia reperfusion [39]. Another explanation may be related to the effect of Allo on renal function improvement and increasing glomerular filtration rate as shown by Neal et al. [40].

On the other hand, it was found that Allo treatment decreased the heart rate significantly even when compared to the normal controlled group which is in accordance with the results of Sakabe et al. [41] which revealed that Allo has 
a protective effect on atrial fibrillation in dogs associated with tachycardia-induced cardiomyopathy. Despite the fact that it was nonsignificant, this bradycardia was associated with increase in the total cycle duration.

Moreover, the current study showed an increased level of TNF- $\alpha$ which is an important inflammatory cytokine that is overexpressed in adipose and other tissues in cases of IR and obesity [42]. This is in accordance with many studies which revealed the role of TNF- $\alpha$ in the induction of IR and type 2 diabetes [43,44]. Although there was no significant change in the lipid profile as mentioned before, this elevated TNF- $\alpha$ may be responsible for the mild increase in the TG and HDL-C and decreased level of LDL. Previous studies showed that hepatic TG and VLDL production are increased in both human and murine studies after TNF$\alpha$ administration $[45,46]$. This may be due to increased hepatic levels of citrate, the rate-limiting enzyme in free fatty acid synthesis [47], or through inhibition of lipoprotein lipase activity [48]. Whereas TNF- $\alpha$-induced changes in TG metabolism are similar in all species, its effect on cholesterol metabolism differs between rodents and primates. Whereas the administration of TNF- $\alpha$ in rodents is followed by increase in hepatic cholesterol synthesis and LDL $[45,49]$, nonhuman primates and humans show either no change or a decrease in serum cholesterol and LDL levels [50]. The mechanisms underlying this species difference are not known. Regarding the elevated HDL-C, it may be related to the inhibitory effect of TNF- $\alpha$ on cholesteryl ester transfer protein (CETP) which transfers cholesteryl esters from HDL to TG-rich lipoproteins leading to high levels of HDL-C [51].

Allo treatment significantly alleviated this increased TNF- $\alpha$ level nearly to the normal control levels which is in accordance with previous studies that showed the reducing effect of Allo on TNF- $\alpha[52,53]$. A novel explanation of this decrease in the TNF- $\alpha$ evidenced by the results of the current study is that it may not be due to direct effect, but may be due to secondary to the ability of the Allo to increase the level of insulin. Beyond its classic metabolic actions, insulin has also anti-inflammatory effect, decreasing the activity of proinflammatory cytokines including TNF$\alpha$ [54]. Unlike many studies which revealed that, in IR, the levels of leptin and resistin increase while adiponectin, which has insulin-sensitizing and anti-inflammatory effect, decreases [55-57], the current study revealed no significant change in adiponectin level. This may be explained by the finding of Shapiro et al. [58] who reported that rats fed fructose ad libitum chronically become leptin resistant with a compensatory increase in adiponectin.

In addition, the results of the present study showed that treatment with Allo has ameliorated and decreased the increased level of $4 \mathrm{HNE}$ that was observed in IR group. It was found that $4 \mathrm{HNE}$ is a biomarker aldehyde of oxidative stress which readily binds covalently to nucleophilic residues of proteins, peptides, phospholipids, and nucleic acids and thereby exhibits cytotoxic effects. $4 \mathrm{HNE}$ can also modulate signaling pathways involved in cell proliferation, fibrosis, apoptosis, and inflammation, which are all hallmarks of cardiovascular diseases [59-61]. Moreover, the current study revealed that Allo treatment decreased significantly Ang II and Ang R1. Angiotensin II directly causes vasoconstriction, increases the release of antidiuretic hormone via release of vasopressin, thus causing the reabsorption of water at the level of the kidneys, and triggers release of aldosterone from the adrenal cortex, causing the kidney to reabsorb sodium [62]. It is assumed that the current study reveals that the ameliorative effect of Allo treatment is not related to its effect on UA and may be related to other mechanisms as the UA in the present model of IR was not significantly increased compared to the normal control group.

In conclusion, the results of the current study show that Allo has a protective effect on vascular complications of IR which may be attributed to the effect of Allo on decreasing the level of TNF- $\alpha$, 4HNE, Ang II, and Ang R1 as well as increasing the level of insulin secretion regardless of the effect of associated dyslipidemia.

\section{Conflict of Interests}

The authors declare that there is no conflict of interests regarding the publication of this paper.

\section{Authors' Contribution}

Hany M. El-Bassossy planned and executed all experiments and prepared the figures and tables and assisted in preparing the paper and data analysis. Ahmed A. Elberry participated in the execution of the experiments and preparing the figures and tables and was responsible for publishing the paper. Ahmad Azhar took part in the design and paper preparation. Salah A. Ghareib planned and supervised the experiment. He also participated in the paper preparation. Abdulrahman M. Alahdal took part in data collection and the preparation of the paper.

\section{Acknowledgment}

The authors would like to thank Mr. Islam Farouk, Department of Pharmacology and Toxicology, Faculty of Pharmacy, King Abdulaziz University, Jeddah, Saudi Arabia, for his effort and help in the experimental study.

\section{References}

[1] B. B. Kahn and J. S. Flier, "Obesity and insulin resistance," The Journal of Clinical Investigation, vol. 106, no. 4, pp. 473-481, 2000.

[2] B. J. Balkau, M. Vray, and E. Eschwege, "Epidemiology of peripheral arterial disease," Journal of Cardiovascular Pharmacology, vol. 23, no. 3, pp. S8-S16, 1994.

[3] B. Isomaa, P. Almgren, T. Tuomi et al., "Cardiovascular morbidity and mortality associated with the metabolic syndrome," Diabetes Care, vol. 24, no. 4, pp. 683-689, 2001.

[4] P. Dandona, A. Aljada, and A. Bandyopadhyay, "Inflammation: the link between insulin resistance, obesity and diabetes," Trends in Immunology, vol. 25, no. 1, pp. 4-7, 2004.

[5] G. S. Hotamisligil, "Inflammation and metabolic disorders," Nature, vol. 444, no. 7293, pp. 860-867, 2006. 
[6] J. W. J. Choi, E. S. Ford, X. Gao, and H. K. Choi, "Sugarsweetened soft drinks, diet soft drinks, and serum uric acid level: the Third National Health and Nutrition Examination Survey," Arthritis Care and Research, vol. 59, no. 1, pp. 109-116, 2008.

[7] D. S. Ludwig, K. E. Peterson, and S. L. Gortmaker, "Relation between consumption of sugar-sweetened drinks and childhood obesity: a prospective, observational analysis," The Lancet, vol. 357, no. 9255, pp. 505-508, 2001.

[8] M. B. Schulze, J. E. Manson, D. S. Ludwig et al., "Sugarsweetened beverages, weight gain, and incidence of type 2 diabetes in young and middle-aged women," The Journal of the American Medical Association, vol. 292, no. 8, pp. 927-934, 2004.

[9] M. Mazzali, J. Hughes, Y.-G. Kim et al., "Elevated uric acid increases blood pressure in the rat by a novel crystalindependent mechanism," Hypertension, vol. 38, no. 5, pp. 11011106, 2001.

[10] U. M. Khosla, S. Zharikov, J. L. Finch et al., "Hyperuricemia induces endothelial dysfunction," Kidney International, vol. 67, no. 5, pp. 1739-1742, 2005.

[11] D. Grassi, L. Ferri, G. Desideri et al., "Chronic hyperuricemia, uric acid deposit and cardiovascular risk," Current Pharmaceutical Design, vol. 19, no. 13, pp. 2432-2438, 2013.

[12] C. A. Roncal, S. Reungjui, L. G. Sánchez-Lozada et al., “Combination of captopril and allopurinol retards fructose-induced metabolic syndrome," American Journal of Nephrology, vol. 30, no. 5, pp. 399-404, 2009.

[13] T. Nakagawa, H. Hu, S. Zharikov et al., "A causal role for uric acid in fructose-induced metabolic syndrome," American Journal of Physiology: Renal Physiology, vol. 290, no. 3, pp. F625F631, 2006.

[14] D. R. Matthews, J. P. Hosker, A. S. Rudenski, B. A. Naylor, D. F. Treacher, and R. C. Turner, "Homeostasis model assessment: insulin resistance and beta-cell function from fasting plasma glucose and insulin concentrations in man," Diabetologia, vol. 28, no. 7, pp. 412-419, 1985.

[15] W. T. Friedewald, R. I. Levy, and D. S. Fredrickson, "Estimation of the concentration of low-density lipoprotein cholesterol in plasma, without use of the preparative ultracentrifuge," Clinical Chemistry, vol. 18, no. 6, pp. 499-502, 1972.

[16] N. Hassan, H. M. El-Bassossy, and M. N. M. Zakaria, "Heme oxygenase-1 induction protects against hypertension associated with diabetes: effect on exaggerated vascular contractility," Naunyn-Schmiedeberg's Archives of Pharmacology, vol. 386, no. 3, pp. 217-226, 2013.

[17] M. F. Mahmoud, N. A. Hassan, H. M. El Bassossy, and A. Fahmy, "Quercetin protects against diabetes-induced exaggerated vasoconstriction in rats: effect on low grade inflammation," PLoS ONE, vol. 8, no. 5, Article ID e63784, 2013.

[18] N. A. Hassan, H. M. El-Bassossy, M. F. Mahmoud, and A. Fahmy, "Caffeic acid phenethyl ester, a 5-lipoxygenase enzyme inhibitor, alleviates diabetic atherosclerotic manifestations: effect on vascular reactivity and stiffness," Chemico-Biological Interactions, vol. 213, no. 1, pp. 28-36, 2014.

[19] J. A. Batsis, R. E. Nieto-Martinez, and F. Lopez-Jimenez, "Metabolic syndrome: from global epidemiology to individualized medicine," Clinical Pharmacology \& Therapeutics, vol. 82, no. 5, pp. 509-524, 2007.

[20] E. Ferrannini, A. Natali, P. Bell, P. Cavallo-Perin, N. Lalic, and G. Mingrone, "Insulin resistance and hypersecretion in obesity," The Journal of Clinical Investigation, vol. 100, no. 5, pp. 1166-1173, 1997.
[21] F. Stirpe, E. D. Corte, E. Bonetti, A. Abbondanza, A. Abbati, and F. de Stefano, "Fructose-induced hyperuricaemia," The Lancet, vol. 2, no. 7686, pp. 1310-1311, 1970.

[22] P. U. Heuckenkamp and N. Zöllner, "Fructose-induced hyperuricaemia," The Lancet, vol. 1, no. 7703, pp. 808-809, 1971.

[23] S. M. Haffner, "Epidemiology of insulin resistance and its relation to coronary artery disease," American Journal of Cardiology, vol. 84, no. 1A, pp. 11J-14J, 1999.

[24] H. P. Friedl, G. O. Till, U. S. Ryan, and P. A. Ward, "Mediatorinduced activation of xanthine oxidase in endothelial cells," The FASEB Journal, vol. 3, no. 13, pp. 2512-2518, 1989.

[25] P. M. Hassoun, F.-S. Yu, C. G. Cote et al., "Upregulation of xanthine oxidase by lipopolysaccharide, interleukin-1, and hypoxia: role in acute lung injury," American Journal of Respiratory and Critical Care Medicine, vol. 158, no. 1, pp. 299-305, 1998.

[26] S. Tan, S. Gelman, J. K. Wheat, and D. A. Parks, "Circulating xanthine oxidase in human ischemia reperfusion," Southern Medical Journal, vol. 88, no. 4, pp. 479-482, 1995.

[27] S. Spiekermann, U. Landmesser, S. Dikalov et al., "Electron spin resonance characterization of vascular xanthine and $\mathrm{NAD}(\mathrm{P}) \mathrm{H}$ oxidase activity in patients with coronary artery disease: relation to endothelium-dependent vasodilation," Circulation, vol. 107, no. 10, pp. 1383-1389, 2003.

[28] J. W. de Jong, R. G. Schoemaker, R. de Jonge et al., "Enhanced expression and activity of xanthine oxidoreductase in the failing heart," Journal of Molecular and Cellular Cardiology, vol. 32, no. 11, pp. 2083-2089, 2000.

[29] P. C. Panus, S. A. Wright, P. H. Chumley, R. Radi, and B. A. Freeman, "The contribution of vascular endothelial xanthine dehydrogenase/oxidase to oxygen-mediated cell injury," Archives of Biochemistry and Biophysics, vol. 294, no. 2, pp. 695702, 1992.

[30] R. Radi, H. Rubbo, K. Bush, and B. A. Freeman, "Xanthine oxidase binding to glycosaminoglycans: kinetics and superoxide dismutase interactions of immobilized xanthine oxidaseheparin complexes," Archives of Biochemistry and Biophysics, vol. 339, no. 1, pp. 125-135, 1997.

[31] H. M. El-Bassossy, M. A. El-Moselhy, and M. F. Mahmoud, "Pentoxifylline alleviates vascular impairment in insulin resistance via TNF- $\alpha$ inhibition," Naunyn-Schmiedeberg's Archives of Pharmacology, vol. 384, no. 3, pp. 277-285, 2011.

[32] M. Brownlee, A. Cerami, and H. Vlassara, "Advanced glycosylation end products in tissue and the biochemical basis of diabetic complications," The New England Journal of Medicine, vol. 318, no. 20, pp. 1315-1321, 1988.

[33] N. Sakata, J. Meng, S. Jimi, and S. Takebayashi, "Nonenzymatic glycation and extractability of collagen in human atherosclerotic plaques," Atherosclerosis, vol. 116, no. 1, pp. 63-75, 1995.

[34] P. H. McNulty, S. M. Ettinger, I. C. Gilchrist, M. Kozak, and C. E. Chambers, "Cardiovascular implications of insulin resistance and non-insulin-dependent diabetes mellitus," Journal of Cardiothoracic and Vascular Anesthesia, vol. 15, no. 6, pp. 768-777, 2001.

[35] J.-Y. Park, N. Takahara, A. Gabriele et al., "Induction of endothelin-1 expression by glucose an effect of protein kinase C activation," Diabetes, vol. 49, no. 7, pp. 1239-1248, 2000.

[36] I. Hulin, S. Kinova, L. Paulis, P. Slavkovsky, I. Duris, and B. Mravec, "Diastolic blood pressure as a major determinant of tissue perfusion: potential clinical consequences," Bratislavské Lekárske Listy, vol. 111, no. 1, pp. 54-56, 2010. 
[37] T. E. Strandberg and K. Pitkala, "What is the most important component of blood pressure: systolic, diastolic or pulse pressure?" Current Opinion in Nephrology and Hypertension, vol. 12, no. 3, pp. 293-297, 2003.

[38] C. A. J. Farquharson, R. Butler, A. Hill, J. J. F. Belch, and A. D. Struthers, "Allopurinol improves endothelial dysfunction in chronic heart failure," Circulation, vol. 106, no. 2, pp. 221-226, 2002.

[39] X. Gao, H. Zhang, S. Belmadani et al., "Role of TNF- $\alpha-$ induced reactive oxygen species in endothelial dysfunction during reperfusion injury," American Journal of Physiology: Heart and Circulatory Physiology, vol. 295, no. 6, pp. H2242H2249, 2008.

[40] D. A. J. Neal, B. D. M. Tom, A. E. S. Gimson, P. Gibbs, and G. J. M. Alexander, "Hyperuricemia, gout, and renal function after liver transplantation," Transplantation, vol. 72, no. 10, pp. 16891691, 2001.

[41] M. Sakabe, A. Fujiki, T. Sakamoto, Y. Nakatani, K. Mizumaki, and $\mathrm{H}$. Inoue, "Xanthine oxidase inhibition prevents atrial fibrillation in a canine model of atrial pacing-induced left ventricular dysfunction," Journal of Cardiovascular Electrophysiology, vol. 23, no. 10, pp. 1130-1135, 2012.

[42] K. E. Wellen and G. S. Hotamisligil, "Inflammation, stress, and diabetes," The Journal of Clinical Investigation, vol. 115, no. 5, pp. 1111-1119, 2005.

[43] K. T. Uysal, S. M. Wiesbrock, M. W. Marino, and G. S. Hotamisligil, "Protection from obesity-induced insulin resistance in mice lacking TNF-alpha function," Nature, vol. 389, no. 6651, pp. 610-614, 1997.

[44] P. A. Kern, S. Ranganathan, C. Li, L. Wood, and G. Ranganathan, "Adipose tissue tumor necrosis factor and interleukin-6 expression in human obesity and insulin resistance," The American Journal of Physiology-Endocrinology and Metabolism, vol. 280, no. 5, pp. E745-E751, 2001.

[45] R. A. Memon, C. Grunfeld, A. H. Moser, and K. R. Feingold, "Tumor necrosis factor mediates the effects of endotoxin on cholesterol and triglyceride metabolism in mice," Endocrinology, vol. 132, no. 5, pp. 2246-2253, 1993.

[46] M. L. Sherman, D. R. Spriggs, K. A. Arthur, K. Imamura, E. Frei III, and D. W. Kufe, "Recombinant human tumor necrosis factor administered as a five-day continuous infusion in cancer patients: phase I toxicity and effects on lipid metabolism," Journal of Clinical Oncology, vol. 6, no. 2, pp. 344-350, 1988.

[47] C. Grunfeld, J. A. Verdier, R. Neese, A. H. Moser, and K. R. Feingold, "Mechanisms by which tumor necrosis factor stimulates hepatic fatty acid synthesis in vivo," Journal of Lipid Research, vol. 29, no. 10, pp. 1327-1335, 1988.

[48] K. R. Feingold, M. Marshall, R. Gulli, A. H. Moser, and C. Grunfeld, "Effect of endotoxin and cytokines on lipoprotein lipase activity in mice," Arteriosclerosis and Thrombosis, vol. 14, no. 11, pp. 1866-1872, 1994.

[49] C. Grunfeld, M. Soued, S. Adi, A. H. Moser, C. A. Dinarello, and K. R. Feingold, "Evidence for two classes of cytokines that stimulate hepatic lipogenesis: relationships among tumor necrosis factor, interleukin-1 and interferon-alpha," Endocrinology, vol. 127, no. 1, pp. 46-54, 1990.

[50] R. Zimmermann, J. G. Strauss, G. Haemmerle et al., "Fat mobilization in adipose tissue is promoted by adipose triglyceride lipase," Science, vol. 306, no. 5700, pp. 1383-1386, 2004.

[51] I. Hardardóttir, A. H. Moser, J. Fuller, C. Fielding, K. Feingold, and C. Grünfeld, "Endotoxin and cytokines decrease serum levels and extra hepatic protein and mRNA levels of cholesteryl ester transfer protein in Syrian hamsters," The Journal of Clinical Investigation, vol. 97, no. 11, pp. 2585-2592, 1996.

[52] U. Demirel, M. Yalniz, C. Aygün et al., "Allopurinol ameliorates thioacetamide-induced acute liver failure by regulating cellular redox-sensitive transcription factors in rats," Inflammation, vol. 35, no. 4, pp. 1549-1557, 2012.

[53] F. D. Rachmat, J. Rachmat, S. Sastroasmoro, and S. I. Wanandi, "Effect of allopurinol on oxidative stress and hypoxic adaptation response during surgical correction of tetralogy of fallot," Acta medica Indonesiana, vol. 45, no. 2, pp. 94-100, 2013.

[54] P. Dandona, A. Aljada, P. Mohanty et al., "Insulin inhibits intranuclear nuclear factor $\kappa \mathrm{B}$ and stimulates $\mathrm{I} \kappa \mathrm{B}$ in mononuclear cells in obese subjects: evidence for an anti-inflammatory effect?" The Journal of Clinical Endocrinology and Metabolism, vol. 86, no. 7, pp. 3257-3265, 2001.

[55] K. E. Wellen and G. S. Hotamisligil, "Obesity-induced inflammatory changes in adipose tissue," The Journal of Clinical Investigation, vol. 112, no. 12, pp. 1785-1788, 2003.

[56] P. Trayhurn and I. S. Wood, "Adipokines: inflammation and the pleiotropic role of white adipose tissue," British Journal of Nutrition, vol. 92, no. 3, pp. 347-355, 2004.

[57] J. G. Neels and J. M. Olefsky, "Inflamed fat: what starts the fire?" The Journal of Clinical Investigation, vol. 116, no. 1, pp. 33-35, 2006.

[58] A. Shapiro, W. Mu, C. Roncal, K.-Y. Cheng, R. J. Johnson, and P. J. Scarpace, "Fructose-induced leptin resistance exacerbates weight gain in response to subsequent high-fat feeding," The American Journal of Physiology-Regulatory Integrative and Comparative Physiology, vol. 295, no. 5, pp. R1370-R1375, 2008.

[59] G. Poli and R. J. Schaur, "4-Hydroxynonenal in the pathomechanisms of oxidative stress," IUBMB Life, vol. 50, no. 4-5, pp. 315-321, 2000.

[60] S. J. Chapple, X. Cheng, and G. E. Mann, "Effects of 4hydroxynonenal on vascular endothelial and smooth muscle cell redox signaling and function in health and disease," Redox Biology, vol. 1, no. 1, pp. 319-331, 2013.

[61] C. M. Spickett, "The lipid peroxidation product 4-hydroxy-2nonenal: advances in chemistry and analysis," Redox Biology, vol. 1, no. 1, pp. 145-152, 2013.

[62] R. M. Berne, M. N. Levy, and B. M. Koeppen, Physiology, Mosby, St. Louis, Mo, USA, 6th edition, 2009. 


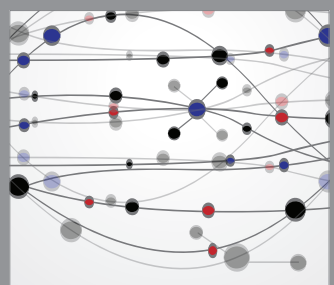

The Scientific World Journal
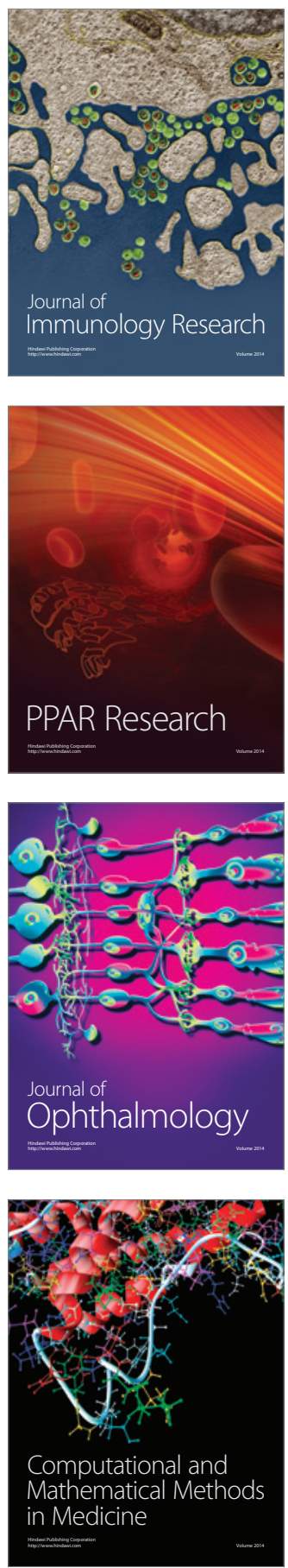

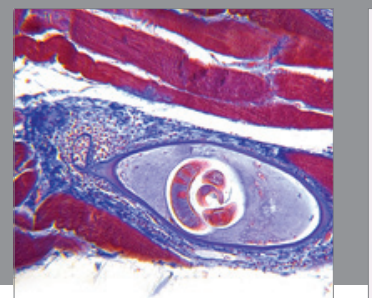

Gastroenterology

Research and Practice
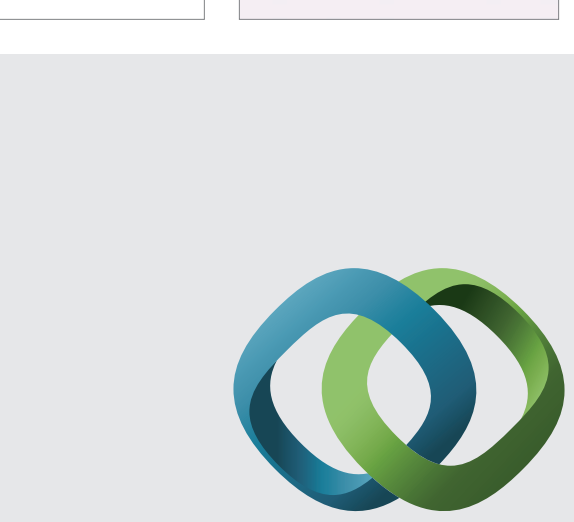

\section{Hindawi}

Submit your manuscripts at

http://www.hindawi.com
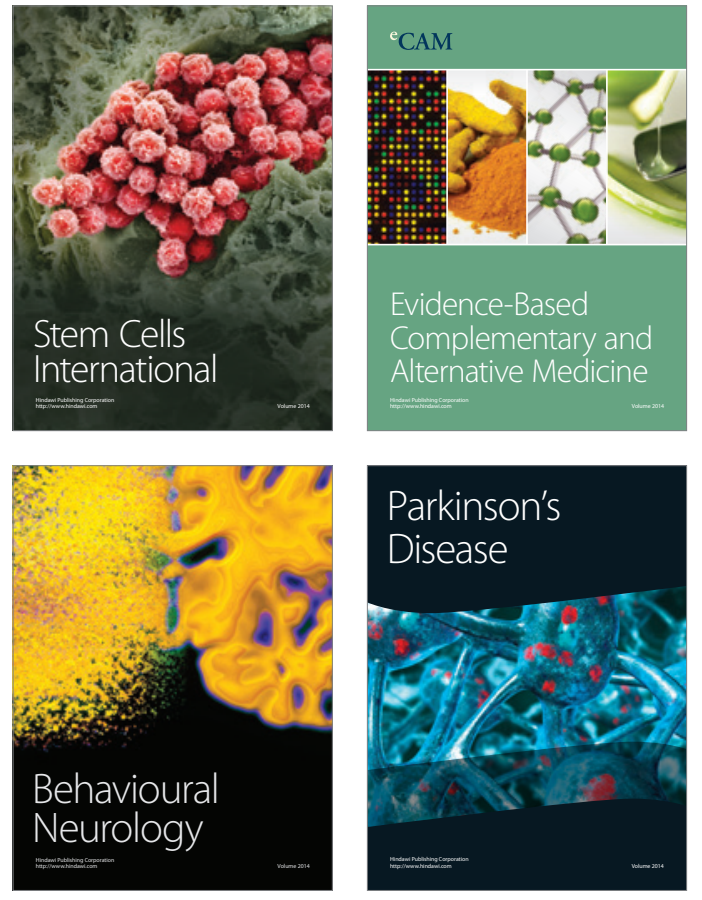
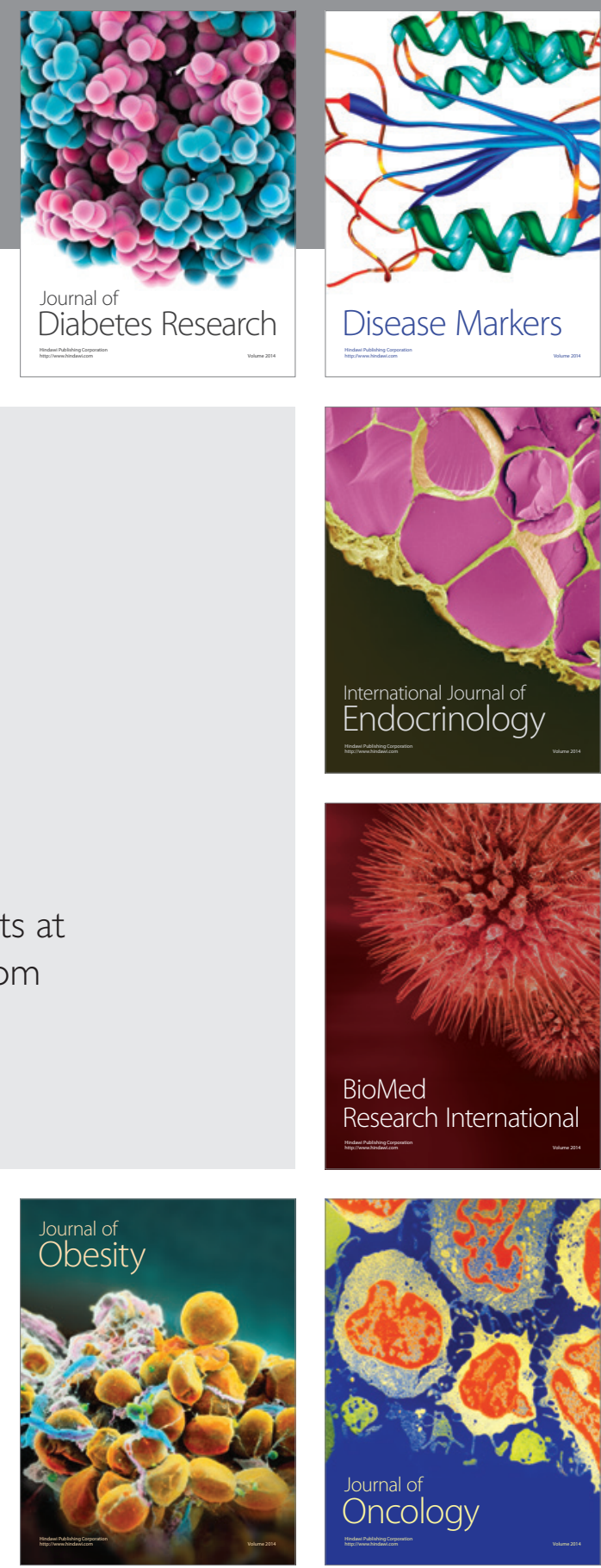

Disease Markers
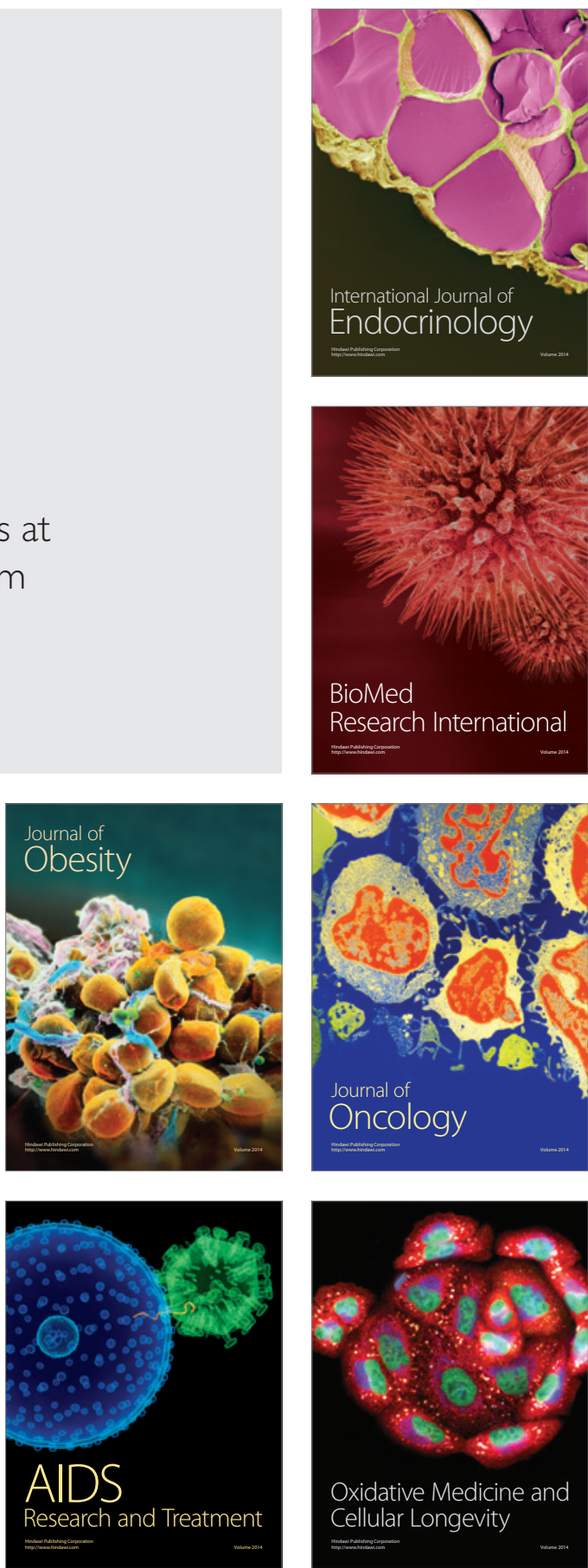